Revista Herencia Vol. 29 (1), 07-20, 2016

Recibido 14-12-2015 Aprobado 10-01-2016

\title{
LA COMIDA EN LAS ALFORJAS
}

\begin{abstract}
REsUmen
Se presenta una descripción de la tradición alimentaria asociada con la preparación de comidas para largas travesías, empacada en hojas de plátano y transportada en alforjas. Para ello se hizo la consulta a un grupo de veinte personas mayores entre 70 y 97 años de edad del Gran Área Metropolitana. La alforja es una especie de bolsa de mecate que era común su uso en la antigüedad para transportar la comida. Como principales alimentos sobresalen la tortilla, el huevo y los frijoles, así como el uso de productos que crecían de forma silvestre o eran producidos en las pequeñas fincas. En el caso de las bebidas era común la elaboración de aguadulce con limón ácido o fresco de avena almacenados en botella de vidrio tapada con un pedazo de olote; mientras que de postre era usual un pedazo de tapa de dulce o panela. De un tema relativamente sencillo, como lo es la práctica de almacenar, conservar y transportar la comida envuelta en hojas y protegida en una alforja, se muestra una información sumamente relevante que contribuye a la comprensión de las prácticas alimentarias tradicionales, resaltándose elementos tales como el uso de hoja de plátano, los constituyentes de la comida del viajero y las expresiones lingüisticas que muestran un entretejido cultural de gran simbolismo.
\end{abstract}

Palabras clave: cocina tradicional, cocina costarricense.

Patricia Sedó Masis.

Docente Catedrática de la Escuela de Nutrición de la Universidad de Costa Rica. Cuenta con una Licenciatura en Nutrición UCR, Maestría Académica en Gerontología de la UCR y Maestría

Profesional en Administración Educativa de la Universidad Latina. Labora en la UCR desde 1989 dedicada a estudio de los alimentos y las tradiciones alimentarias de Costa Rica, así como en la atención nutricional de población adulta mayor. Desde el 2003 es responsable del proyecto de Trabajo Comuna Universitario en el tema de conservación y revitalización de la cocina tradicional costarricense.patricia.sedo@

ucr.ac.cr

\section{Abstract}

It is a description of the food tradition associated with the preparation of meals for long journeys, packed in banana leaves and carried in saddlebags. This consultation was made to a group of twenty elderly people between 70 and 97 years of age of the greater Metropolitan Area. The saddlebag is a kind of bag of rope that was used to transport the food wrapped in banana leaf. As main foods are tortilla, egg and beans, as well as the use of products those grew wild or were produced on small farms. In the case of beverages, it was common to the elaboration of "aguadulce" with lemon of oats stored in glass bottle. A relatively simple issue, as it is the practice of storing, conserving and transporting food wrapped in banana leaves and protected in a saddlebag, shows a highly relevant information that contributes to the understanding of the practical food traditional, emphasizing elements such as the use of leaf of banana, the constituents of the food of the traveller and the linguistic expressions that show a cultural interweaving of great symbolism.

Key words: traditional food, Costa Rican foods.

\section{Introducción}

"Un alimento antes de pasar por el estómago vacío, primero debe alimentar la mente colectiva"

\section{Marvin Harris.}

En el presente artículo se describe de manera general una práctica alimentaria tradicional ligada con la vida campesina del costarricense y el uso de la alforja como parte la indumentaria cotidiana. 
Foto 1. Artesanías. Gimena Cortés, Frailes 2014.

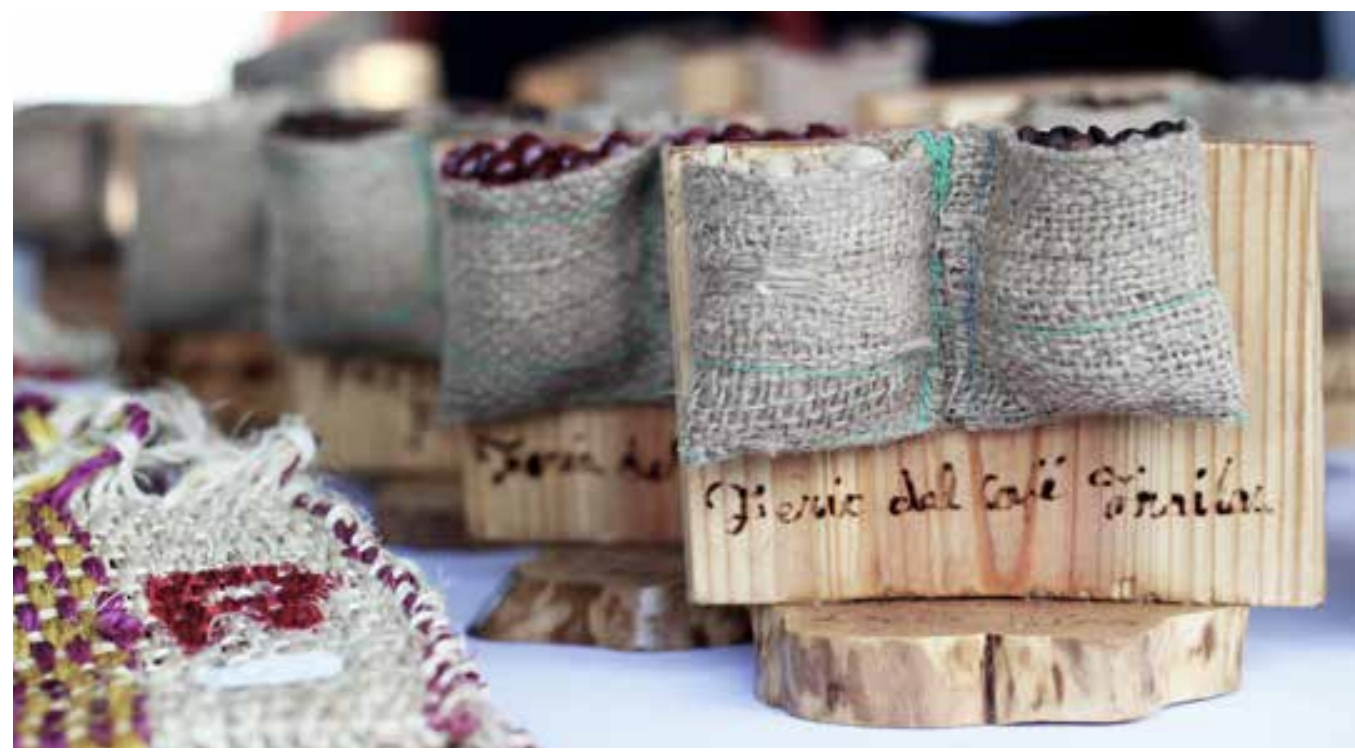

La dieta tradicional muestra muchos matices, como resultado de los procesos de construcción social y los cambios en los patrones de alimentación a lo largo de la historia (Traversa, 2002). Por sí misma, la alimentación es una manifestación cultural, forma parte del patrimonio cultural intangible y engloba aspectos sociales, territoriales, religiosos y económicos (Cervantes, sf).

En el caso de Costa Rica, como parte del proceso sociohistórico, la alimentación es una experiencia intercultural que se vincula con otras manifestaciones como la lingüística, el baile, la música, la vestimenta, la cerámica, las mascaradas, el boyeo y la carreta, las fiestas patronales y otras actividades que para las personas que habitan las diferentes regiones del país se transmiten de generación en generación.

Una considerable parte de las tradiciones alimentarias arraigadas en Costa Rica están relacionadas con la vida en el campo, la labranza de la tierra y la vocación agrícola campesina dominante en los pueblos. Las mismas permanecen vigentes sea porque se conservan en la memoria colectiva o porque también muchas familias aun las viven en su cotidianidad.

A pesar de lo anterior, los cambios acelerados en el estilo de vida del costarricense y el impacto de la globalización, el mercado, la urbanización, el cambio en las actividades productivas y los movimientos migratorios, entre otros aspectos, hacen que los desafíos sean grandes y complejos en la tarea de conservación y revitalización del patrimonio cultural intangible (Dobles y González, 2009).

El 25 de noviembre del 2005, la Organización de Naciones Unidas para la Educación, la Ciencia, y la Cultura (UNESCO, 2005) hizo la promulgación de la tradición del boyeo y la carreta como Patrimonio Cultural Intangible de la Humanidad. Asociado a esta manifestación cultural existen diversas prácticas alimentarias tradicionales, entre ellas la costumbre del boyero de llevar la comida en una alforja.

Profundizar en el estudio de las tradiciones alimentarias amplía las visiones que se tienen sobre ciertas prácticas que parecerían relativamente simples pero que, al hablar de ellas con personas que vivieron la época en que la práctica alimentaria era habitual y una la norma para una mayoría, resulta interesante explorar sobre diversos temas vinculados con la alimentación. Tal es el caso del significado que tiene para los costarricenses los denominados "gallos" o "almuerzos" envueltos en hoja, a los que también se les da el calificativo de "comida campesina" (Sedó, 2008). En esta expresión gastronómica se evidencia la creatividad de las personas 
para aprovechar al máximo los recursos alimentarios disponibles, y la herencia mesoamericana en la constitución de la dieta ancestral, donde destacan el maíz y el frijol (Pérez, sf).

Conocer sobre las prácticas alimentarias tradicionales con mayor profundidad contribuye a fortalecer el valor de la herencia culinaria del país, sin caer en el error de homogenizar o invisibilizar la información, creyendo que ciertas prácticas son irrelevantes o al analizar los temas bajo parámetros extranjeros (Carvajal, sf).

En el marco del proyecto TCU-486 "Contribución a la conservación y revitalización de la cocina tradicional de Costa Rica", durante el 2015 la coordinación del proyecto se propuso desarrollar una investigación sobre tradiciones ligadas con el boyeo y la carreta, a propósito el aniversario de su promulgación como manifestación cultural reconocida mundialmente.

Se entrevistaron veinte personas adultas mayores residentes en Puriscal, Zarcero, Atenas, Llano Grande de Cartago y San Rafael de Heredia con edades entre 70 y 97 años de edad.

El tema central de la entrevista fue el significado para ellos de la comida que se transportaba en la alforja. La información se complementó con una revisión documental sobre el tema.

Paralelamente, integrantes del Club de Amigos de la Cocina Tradicional de Costa Rica, estudiantes del Programa Integral de la Persona Adulta Mayor y jóvenes matriculados en el TCU intercambiaron experiencias sobre la tradición del boyeo, incluyendo un taller de cocina para elaborar los denominados "almuerzos campesinos"

A continuación se describen los principales hallazgos:

\section{La alforja, más que dos bolsas unidas}

La alforja consiste en dos bolsas unidas por dos tiras. La misma está elaborada de un material resistente que puede ser cuero, tela de manta, cabuya, mecate o yute. Las tiras que sujetan los bordes de las bolsas las unen, lo cual facilita su manejo.

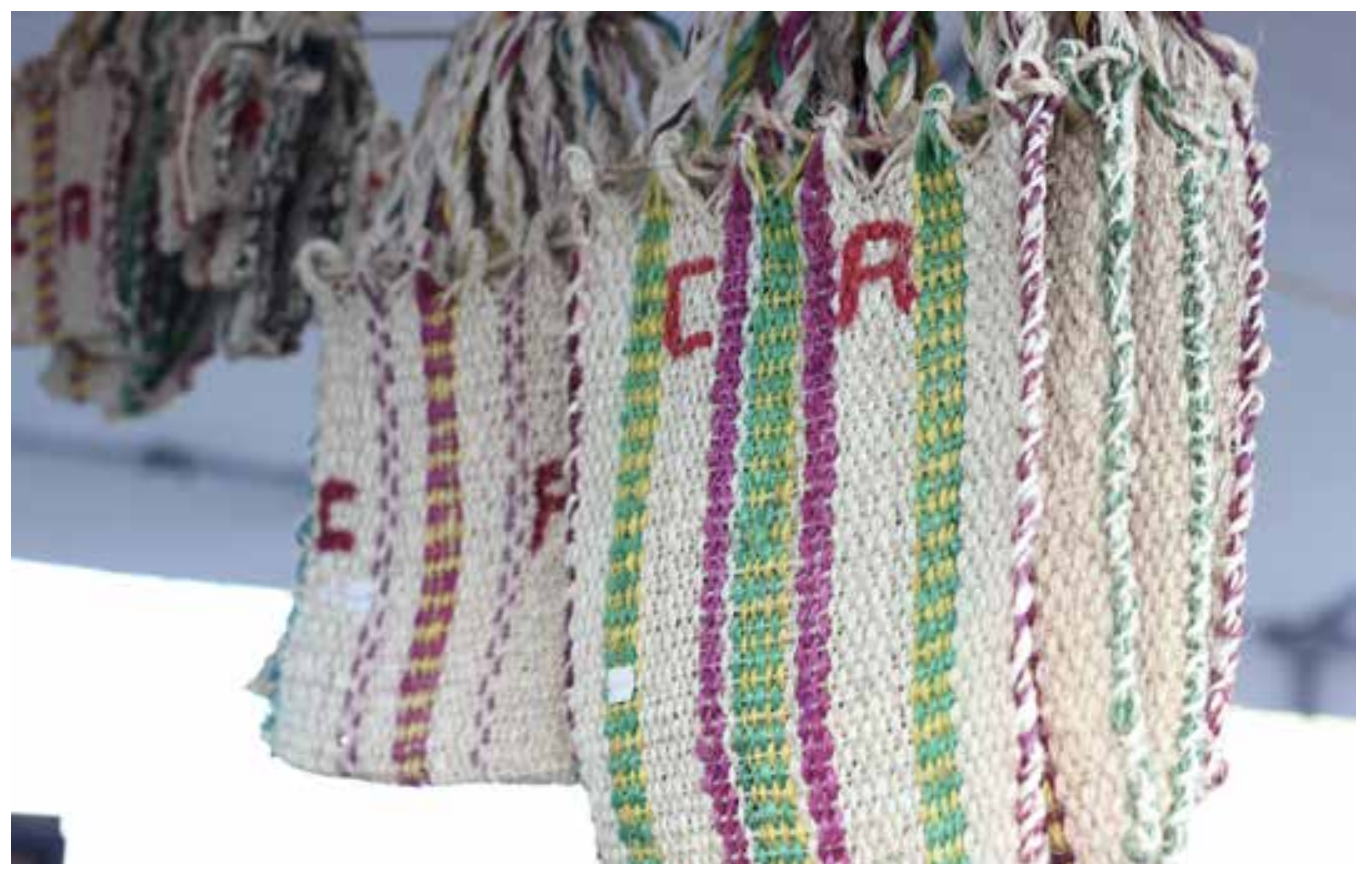


El Diccionario de la Real Academia Española define la alforja como vocablo de origen árabe que significa: "una especie de dos bolsas abiertas por el centro y cerradas por sus extremos, ordinariamente cuadradas, donde, repartiendo el peso para mayor comodidad, se guardan algunas cosas que han de llevarse de una parte a otra".

Este tipo de indumentaria tiene una relación directa con el almacenamiento y transporte de provisiones alimentarias que las personas llevan cuando van de viaje.

Aparentemente, la alforja fue traída a tierras costarricenses por los primeros conquistadores españoles en el siglo XVI, quienes cargaban sus pertenencias básicas en alforjas de cuero colgadas de los lomos de los caballos, y realizaban grandes travesías por tierra, en la tarea de exploración y reconocimiento de las nuevas tierras por conquistar. Es de suponer que en esas alforjas había pan duro, carne de vaca o pescado salado y seco, queso seco, vino y aceite, combinado con alimentos conocidos en América y que por necesidad tuvieron que incorporar en su dieta para sobrevivir (Ascoita, 2010). La alforja es considerada como un implemento necesario para el viajero, donde se pueden transportar alimentos y objetos de primera necesidad para hacer la travesía.

De acuerdo con la consulta realizada a los informantes, el material más común de la alforja del campesino tico es la tejida de cabuya o mecate, la cual es resistente, liviana y de bajo costo.

Se considera un artículo de uso personal, y era común que solamente los hombres la utilizaran. En el caso de las mujeres, la costumbre era transportar la comida envuelta en una servilleta o guardada en un bolso sencillo de mecate. De esta forma vemos la relación directa de esta indumentaria con el jornalero o boyero varón.

La alforja es uno de los implementos más utilizado por el boyero o boyera. Colgado del hombro o en un paral de la carreta, la alforja sirve para transportar la comida y protegerla del polvo o del sol; y también forma parte de su identidad.

\section{Caracterización de la comida transportada en la alforja}

En el mundo doméstico, la preparación de la comida antiguamente era de dominio femenino, y aún lo sigue siendo aunque con una mayor participación de los varones.

Foto 3. Picadillo de palmito de pejibaye, Santiago de Puriscal. Archivo TCU-486.

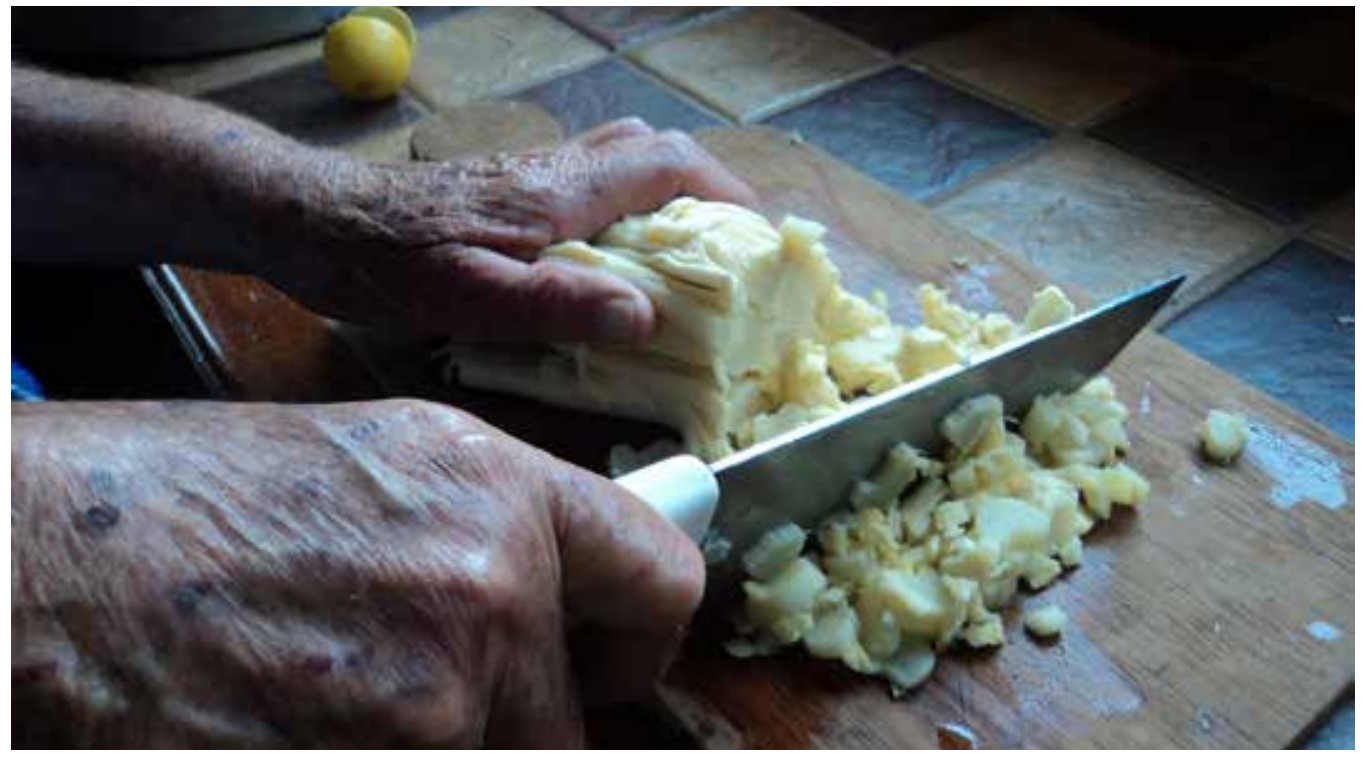




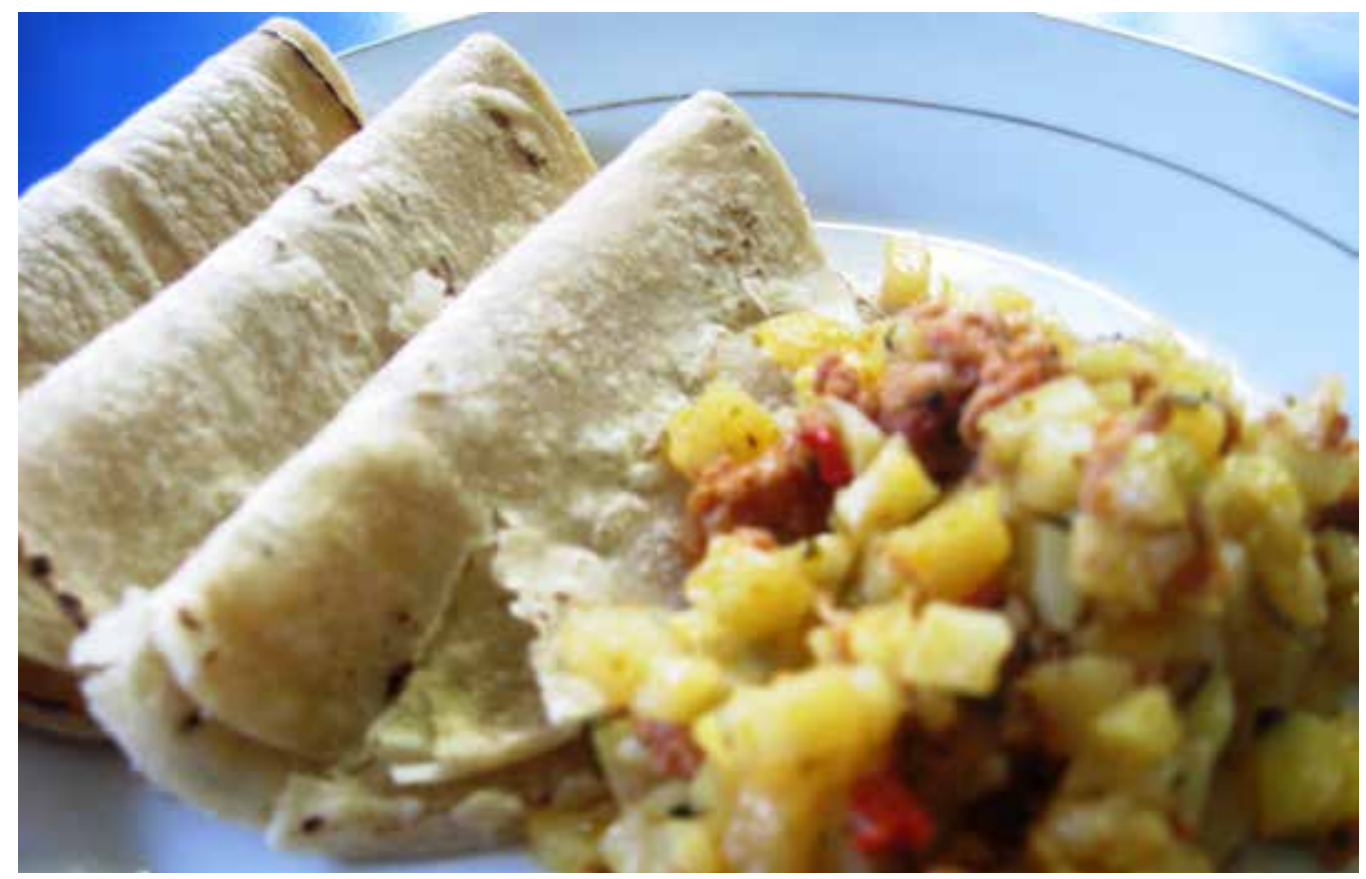

Foto 4. Picadillo de papa con chorizo,

Atenas. Archivo TCU-486.

La selección de los alimentos que podían llevarse en la alforja pasaba por ciertos criterios fundamentales: lo que era posible preparar con los ingredientes disponibles en la casa, el aprovechamiento máximo de los recursos alimentarios que crecían de forma silvestre en los patios o en el cerco, tal como se llamaba al pedazo de tierra cercano a la casa, límite entre la misma y el cafetal, donde se sembraba todo lo que era posible cultivar: ayotes, chayotes, tacacos (Sechium tacaco), yuca, árboles frutales, matas de guineo y plátano, entre otros.

La tortilla aparece como alimento esencial de la comida que se preparaba para ser transportada en la alforja. Como alimento básico, la tortilla se elaboraba preferiblemente con maíz cocido con cal y ceniza y molido en máquina (hace más de cincuenta años no existía la harina de maíz procesada industrialmente).

La cocción del maíz se hacía generalmente el día anterior o en la madrugada. La molienda o preparación de las tortillas se hacía en horas de la madrugada, y las tortillas eran guardadas en una canasta que se colgaba del techo para evitar que el gato, los ratones o insectos las contaminaran.

La tortilla, según Pérez (sf: 21), es considerada como la "hija predilecta del maíz". Antiguamente la masa se obtenía de la molienda del maíz en una piedra de origen volcánico (metate) con un metlapil o mano de metate. Es así como se trituraban los granos de maíz cocidos con ceniza y cal para facilitar el desprendimiento del hollejo, cuyo proceso se llamó "nixtamalización".

Una tortilla, según la describe Pérez, se define como (sf:21):

"la expresión musical de las manos de todas las abuelas, madres e hijas quienes, torteando entre sus manos, crearon esta maravilla que acompaña las mesas mexicanas y que, aunque algunos lo duden, tienen claramente diferenciado el frente y la vuelta, pues una vez que ha sido depositada para su cocción en el comal, la tortilla eleva su temperatura pero se cocina primero del lado de contacto con el comal y la parte superior se reseca por el aire caliente. Tan pronto se sabe-como parte del saber ancestral- el momento de voltear la tortilla, ocurre la magia del frente y la vuelta. Siempre el primer lado cocido es el frente". 
Foto 5. Almuerzo envuelto, Sarchí.

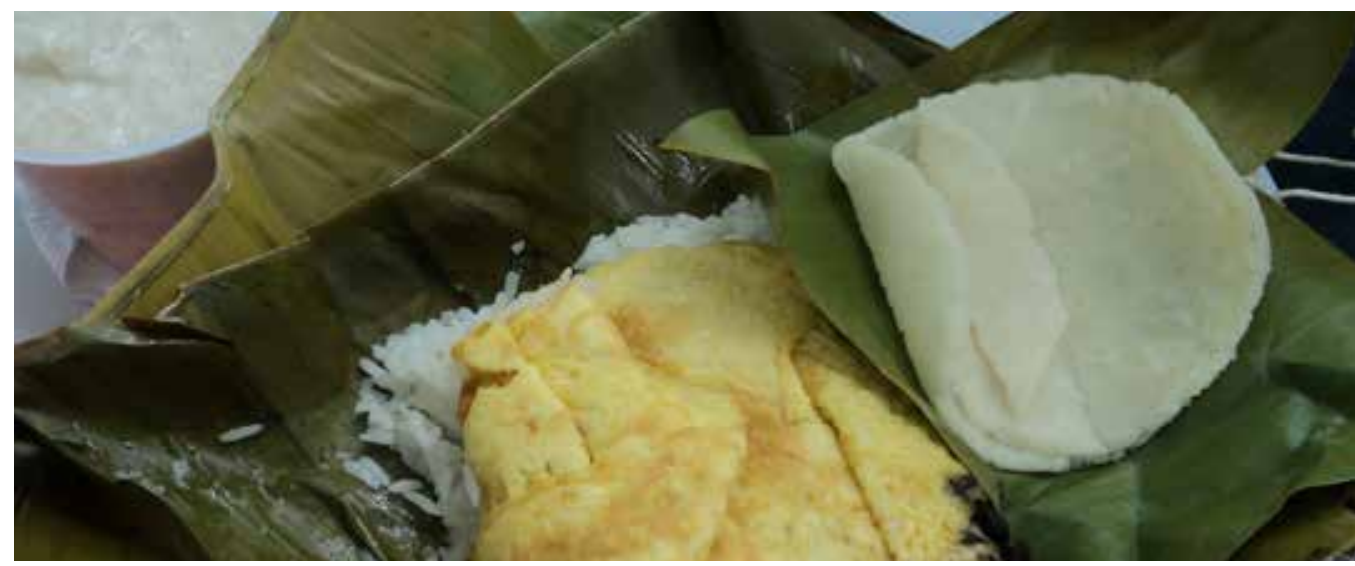

A la descripción de esta autora podemos agregar que en Costa Rica se le llama "cara" a la superficie de la masa que fue palmeada para formar la tortilla y que es colocada sobre el comal caliente para su asado, lo que ella describe como "frente". Encontramos diferencias en tamaños y grosores, si comparamos la tortilla elaborada en el Valle Central y en Guanacaste, siendo de más pequeñas dimensiones en la zona central del país. La tortilla descrita por las personas entrevistadas se caracterizaba por ser de mínimo grosor y con un diámetro que no supera los doce centímetros. Por cada envoltorio de comida almacenada en la alforja pueden utilizarse hasta cuatro tortillas. La tortilla funge como un "plato comestible". Se coloca de forma alternada con el relleno que varía según los alimentos disponibles, ya sean frijoles, queso, un trozo de carne o salchichón. Cada porción de comida, incluida la tortilla, se denomina en Costa Rica como "gallo".

Los huevos era la principal fuente de proteína de origen animal de las familias campesinas hace más de cincuenta años. De igual forma, se acostumbraba disponer de una vaca para la obtención de leche y elaboración del queso para consumo familiar. Estos productos están presentes en la comida guardada en la alforja.

La cantidad de alimento preparado para emprender una travesía era suficiente para alimentar a la persona, pero no al hartazgo. Eran suficientes cuatro tortillas con "algo más" para llenar los estómagos de quienes durante más de seis horas pasaban trabajando bajo el extenuante sol en la labranza de la tierra, o trasladándose de un punto a otro en cabalgata o caravana de carretas.

Foto 6. Envoltura. Puriscal, PS 2013

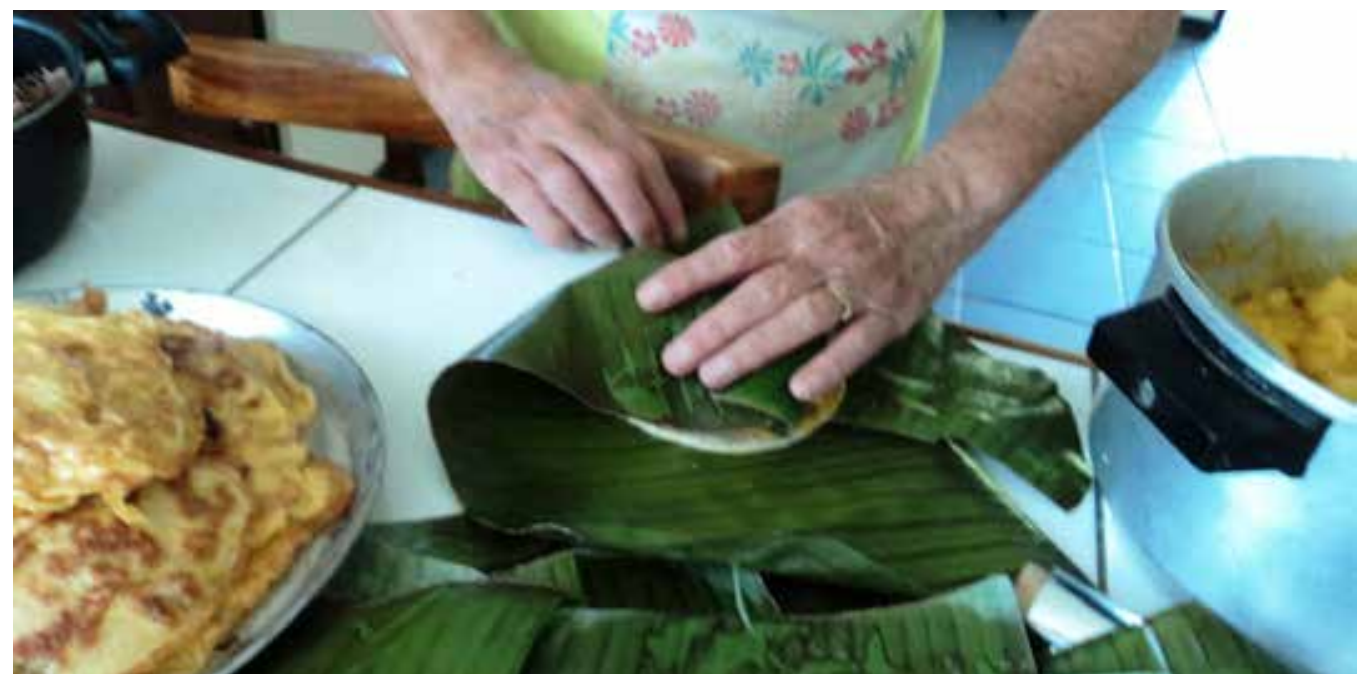




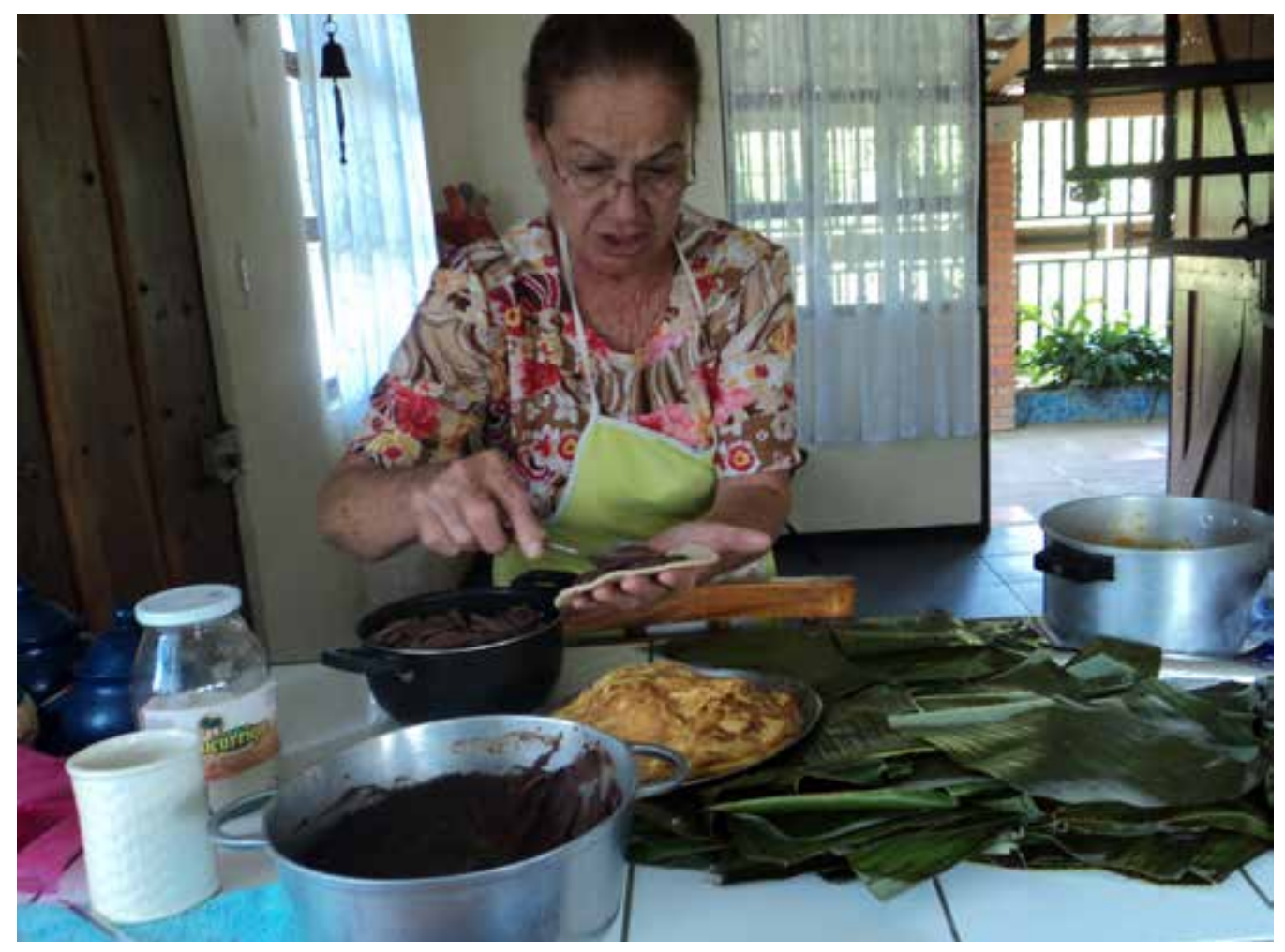

Foto 7. Elaboración de almuerzos. Puriscal, PS 2013

El huevo se consumía de formas variadas, entre las que sobresalían las tortas, el huevo duro o la combinación de huevo con productos que crecían de forma silvestre, como el tomatillo agrio.

Otro producto que no podía faltar eran los frijoles, los cuales generalmente se consumían solos o mezclados con cebolla o culantro coyote. Para evitar que la tortilla se humedeciera, generalmente se eliminaba el caldo, y en un sartén se cocinaban ligeramente con un poco de manteca y cebolla. Los frijoles se majaban con una cuchara o tenedor, y con el calor generado en la superficie del comal se lograba una textura más seca. Este tipo de preparación se conoce popularmente como "frijoles majados" o "frijoles arreglados".

Según las personas entrevistadas, el uso de arroz o plátano maduro frito en la preparación de este tipo de comida envuelta es más contemporáneo. De igual forma se citan las papas achiotadas, elaboradas con papas cocidas y majadas, las cuales se mezclaban con un poco de manteca y achiote.

En cuanto a productos cárnicos, solamente se utilizaban cuando había la celebración de un evento especial, como un paseo familiar. Los alimentos más comunes eran la gallina achiotada, cocida a fuego lento con gran cantidad achiote; asimismo se utilizaba el salchichón o un trozo de carne de res ahumada y ligeramente frita.

La comida empacada en la alforja mantenía su calor por largo tiempo, con lo cual la persona al desenvolverla encontraba una comida tibia cocida a la leña y aromatizada con la hoja.

Antes de partir, el señor recibía de parte de su esposa o alguna hija la alforja cargada con las provisiones alimentarias para el día o para los días que iba a durar fuera de la casa. De un lado de la alforja se colocaba el envoltorio y, en el otro lado, se guardaba la botella con la bebida.

La costumbre era preparar la comida en la madrugada, con la finalidad de que fuera lo más fresca posible. 
En la siguiente tabla se presenta la información referente al tipo de preparaciones comunes en la comida empacada en la alforja:

\section{Descripción de alimentos utilizados de forma tra- dicional para su empaque en la alforja}

\begin{tabular}{|c|c|}
\hline Tipo de alimento & Descripción \\
\hline Bebida & $\begin{array}{l}\text { Aguadulce (agua endulzada con miel de caña o tapa de dulce) } \\
\text { Aguadulce con limón (uso de limón tipo mandarina y miel de } \\
\text { caña o tapa de dulce) } \\
\text { Fresco de limón (agua con jugo de limón ácido criollo) } \\
\text { Agua dulce con avena (agua endulzada con miel de caña o } \\
\text { tapa de dulce y con poca cantidad de hojuelas de avena). } \\
\text { Fresco de chan (Hyptis suaveolens }\end{array}$ \\
\hline $\begin{array}{l}\text { Frijoles } \\
\text { Huevo }\end{array}$ & $\begin{array}{l}\text { Frijoles arreglados } \\
\text { Frijoles majados } \\
\text { Torta de huevo con quelites (torta de huevo con brotes tiernos } \\
\text { de chayote o ayote). } \\
\text { Guiso de huevo con quelites, flores u hojas (mezcla de huevo } \\
\text { con brotes tiernos o flores de ayote, itabo ( Yucca } \\
\text { guatemalensis), poró (Erythrina berteroana) o madero negro } \\
\text { (Gliricidia sepium). También era común el uso de verdolaga } \\
\text { (Portulaca aleracea), culantro coyote (Eryngium foetidum), } \\
\text { entre otros. } \\
\text { Huevo con tomatillo agrio (mezcla de huevo con tomatillo } \\
\text { silvestre (Licopesicum esculentum var. ceraciforme) }\end{array}$ \\
\hline $\begin{array}{l}\text { Productos } \\
\text { cárnicos o } \\
\text { derivados lácteos }\end{array}$ & $\begin{array}{l}\text { Carne de res ahumada (forma de conservación tradicional con } \\
\text { sal y humo). } \\
\text { Gallina arreglada o achiotada (trozos de gallina cocida a fuego } \\
\text { lento con olores y suficiente achiote). } \\
\text { Queso semiduro o ahumado }\end{array}$ \\
\hline $\begin{array}{l}\text { Otros alimentos } \\
\text { incluidos en los } \\
\text { envoltorios }\end{array}$ & $\begin{array}{l}\text { Papas achiotadas (papas cocidas, majadas y mezcladas con } \\
\text { manteca, achiote y cebolla). } \\
\text { Picadillos a base de papa, arracache o plátano verde. }\end{array}$ \\
\hline $\begin{array}{l}\text { Golosinas o } \\
\text { alimentos } \\
\text { complementarios }\end{array}$ & $\begin{array}{l}\text { Bizcocho o pan casero } \\
\text { Pedazos de tapa de dulce como golosina o postre. } \\
\text { Bananos } \\
\text { Frutas que recolectaban de los árboles a lo largo del camino, } \\
\text { entre las que estaban naranjas, guayabas ( Psidium guajava), } \\
\text { guapinoles (Hymenaea courbaril) o nísperos (Eriobotrya } \\
\text { japónica). }\end{array}$ \\
\hline
\end{tabular}

Elaboración propia, 2015.

Desde el punto de vista nutricional se nota un balance en la selección de las comidas, con alimentos energéticos necesarios para largas travesías, donde la ración de la comida debe satisfacer la necesidad de hambre y saciedad. 
Las porciones relativamente pequeñas, en comparación con la actividad física y agotamiento que provocaba el trabajo de campo y las largas travesías a pie, hace pensar que la selección de las comidas se lleva a cabo tomando como criterio la densidad energética y nutricional tenía buenos resultados.

Otro aspecto a señalar es la elección de alimentos que se conservaban en buen estado por un tiempo prolongado sin refrigeración, con lo cual se podría pensar que las técnicas de cocción aplicadas y la protección con la hoja de plátano prolongaban de cierta forma la vida útil de los productos.

Los tipos de bebida favorecían la hidratación, la obtención de energía a partir de la miel utilizada, y provisión de vitamina $\mathrm{C}$ del jugo de limón.

Al hacer una estimación del aporte nutricional de un "almuerzo campesino" tomando en cuenta la ración básica de cuatro tortillas, una torta de huevo, un gallo de frijoles arreglados y una botella de aguadulce con limón es de $600 \mathrm{Kcal}$, lo cual representa cerca de un $30 \%$ de las necesidades energéticas promedio de una persona adulta $(2000 \mathrm{Kcal})$.

\section{La hoja de plátano en la cocina tradicional costa- rricense}

El uso de las hojas de variados productos obtenidos de las zonas boscosas para almacenar, conservar y cocinar los alimentos es una muestra del conocimiento ancestral acumulado, enriquecido por la observación detallada de la naturaleza y la experimentación en el mundo doméstico.

En el caso de la cocina mesoamericana prehispánica, de la cual tenemos gran influencia, Pérez (sf) indica el uso común de las hojas de hoja santa o yerba santa, tusas, aguacate o de maguey para envolver, asolear y deshidratar o cocinar los alimentos.

La selección de las hojas se hacía tomando en cuenta las fibras húmedas o secas, de acuerdo con la técnica aplicada, y las propiedades aromáticas que las mismas tienen y que otorgan un sabor diferenciado a los alimentos que tenían contacto con estos follajes.

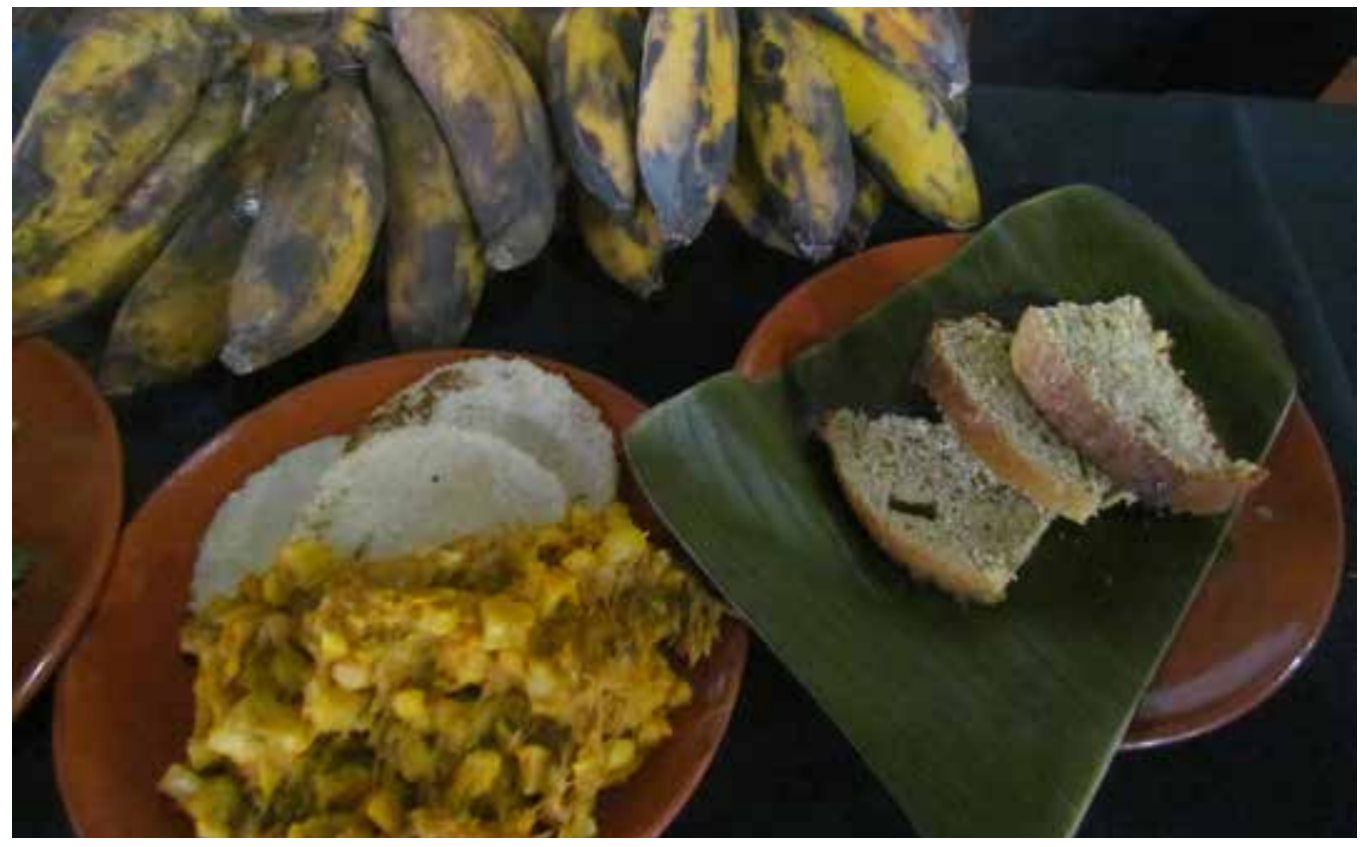

Foto 8. Picadillo de guinea verde y pan de guinea madura.

Museo Cultura

Popular UNA-Escuela e Nutrición, UCR. 
No se dispone información del momento en que en Costa Rica comenzó a usarse con mayor popularidad la hoja de plátano para la envoltura de alimentos, aunque es de suponer que su alta disponibilidad, y por ser un cultivo anual, es posible obtener fácilmente las hojas en cualquier momento del año.

En estudios realizados en la Escuela de Nutrición de la UCR se ha registrado el uso de la tusa u hoja del maíz fresca o seca, la hoja del palo de almendro, la hoja de bijagua y de ayote para envoltura; también se usa la hoja de caña, higo, jocote y hasta mango para resaltar el sabor de ciertas comidas dulces (Escuela de Nutrición, 2015).

Antiguamente era común el empaque de las tapas de dulce en hoja de caña seca; de igual forma la hoja de bijagua (Calathea lutea) se utilizaba ampliamente para envolver la sal, carne y verduras.

En cuanto al uso de la hoja de plátano para la envoltura de alimentos, en el caso de Costa Rica hasta poco más de cuarenta años era común la práctica en los comercios para envolver ciertos alimentos en hoja, entre ellos la carne.

En el marco del proyecto TCU-486 se tienen registradas historias de personas que en su infancia eran contratadas por las carnicerías del pueblo para conseguir en grandes cantidades las hojas de plátano; o bien, la venta de carne a domicilio por parte de personas que la transportaban en saco y empacada en hojas de plátano y la entregaban en las casas, según los pedidos realizados.

La práctica de envolver la carne en hojas o papel periódico impreso fue prohibida por el Ministerio de Salud desde hace varias décadas, y actualmente se empaca en plástico.

Aunque no sea un producto comestible debido a su difícil digestión por el alto contenido de lignina y otras fibras insolubles, la hoja de plátano (de la especie Musaceae) ocupa un lugar especial en la alimentación tradicional de Costa Rica como medio para almacenar, servir o cocinar alimentos.

Como referente en otras culturas alrededor del mundo, la historia ancestral gastronómica evidencia el uso de la hoja de plátano para servir los alimentos a manera de plato, para la cocción y envoltura, con lo cual forma parte de las tradiciones alimentarias, tal es el caso en Asia, África, México, Suramérica y pueblos caribeños.

En ceremonias hindúes, es común el uso de las hojas de plátano como elemento decorativo; mientras que en países del Caribe, África y Asia es común utilizar la hoja para la cocción a fuego lento o directamente en las brasas.

Las hojas de plátano están consideradas entre las más grandes del reino vegetal. Las mismas contienen sustancias orgánicas que con el contacto del calor desprenden componentes aromáticos anisados que, en el caso de los alimentos, impregnan un aroma y un sabor característico.

Compuestos fenólicos y otras sustancias orgánicas presentes en las hojas de plátano también han sido estudiadas por atribuírseles popularmente propiedades medicinales (Fernández et al., 1997).

La resistencia y el tamaño de las hojas, la impermeabilidad, así como su durabilidad, aun cuando se exponen a temperaturas altas, son las principales características por las cuales comenzaron a utilizarse ampliamente como material de envoltorio para conservar semillas, sal, y alimentos preparados. Además, se descubrió que podía utilizarse para tapar la comida e inclusive envolverla y cocinarla, evitándose la entrada de agua al interior del alimento. La impermeabilidad se asocia con el recubrimiento de la superficie de las hojas con aceites esenciales que repelen el agua. Es por tal razón que comenzó a utilizarse como sustituto de la hoja de maíz para la elaboración de los tamales.

Tan arraigado está el uso de hojas de plátano para la elaboración de determinados platillos que no es posible pensar la elaboración sin depender de las mismas, tal como ocurre con la elaboración de los tamales. 


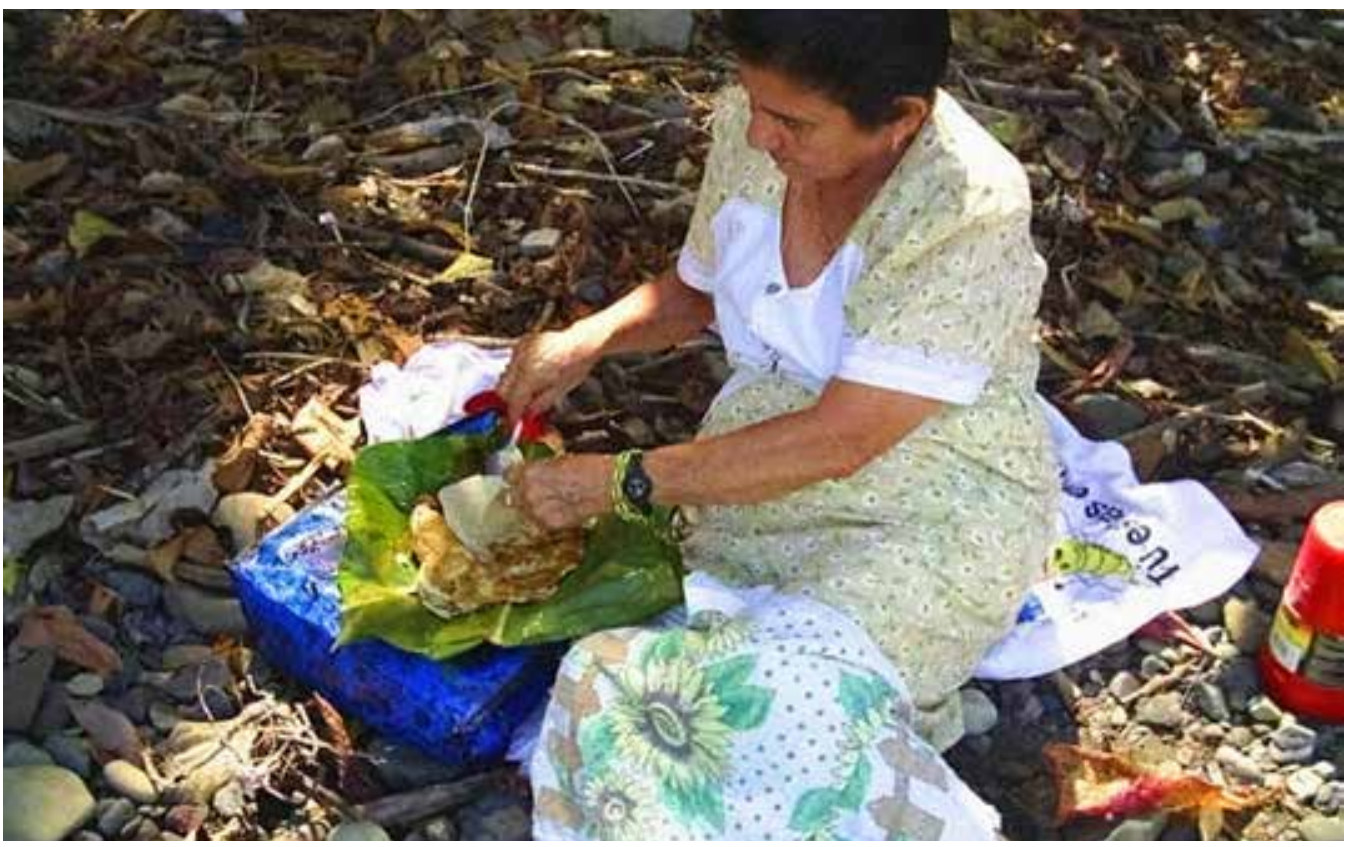

Foto 9. Almorzando en Playa Agujas, PS

La envoltura de la comida en la hoja de plátano tiene la doble función de protección y mantenimiento del calor. Los aceites presentes en la hoja impregnan el sabor característico a los alimentos envueltos en ella, con lo cual la comida empacada de esta forma tiene un aroma y sabor particular, y el aroma se intensifica cuando se da el calentamiento, lo cual provoca la liberación de los compuestos y el ablandamiento de la hoja.

En la actualidad, la costumbre de preparar la comida envuelta en hoja se identifica con la cocina tradicional. Las diferencias en el contenido del tradicional "almuerzo" se presentan según la región y la ocasión. Así, por ejemplo, familias de Puriscal acostumbran elaborar picadillo con hojas de zorrillo (Cestrum racemosum) o chicasquil (Cnidosculus acunitifolius); mientras que en Sarchí se acostumbra elaborar papa achotada o picadillo de arracache (Arracacia xanthorriza), y en Atenas la práctica tradicional es agregar frijoles blancos y carne de cerdo al picadillo de papa.

Por su parte, en los restaurantes dedicados a la venta de comida tradicional se ofrecen los productos en una tabla de madera cubierta con hoja de plátano, mientras que en el Mercado Central de San José es popular el puesto de doña Tala y su popular "Tala Pinto", compuesto por gallo pinto acompañado de torta de huevo, queso o carne y plátano maduro frito envuelto en hoja de plátano.

De esta forma, aunque en la actualidad y, principalmente en zonas urbanas, no existe la costumbre de envolver la comida en hojas de plátano en el contexto cotidiano, el posicionamiento de esta forma de consumo en restaurantes de cocina tradicional contribuye a que en el colectivo se asocie esta práctica con la dieta tradicional.

La comida envuelta en hojas comenzó a llamarse "almuerzo campesino", por cuanto la ración de comida se consumía a la hora de almuerzo, y no tanto en otros tiempos de comida. Se califica como "comida campesina", según los informantes, por la preparación sencilla y de bajo costo, así como por los ingredientes utilizados. También comenzó a llamarse "almuerzo envuelto" debido a la costumbre de envolver la comida primero con hoja de plátano soasada, y luego con una servilleta de manta. 


\section{Sentimientos asociados con la comida transporta- da en la alforja}

La comida típica de una alforja evoca en las personas entrevistadas recuerdos de su infancia y la vida en el campo, las travesías familiares en carreta para visitar un familiar lejano, ir a una fiesta patronal o a un paseo en carreta. También trae recuerdos asociados con la colaboración que se solicitaba a los niños y jóvenes de las familias numerosas para que llevaran la comida a sus papás o hermanos mayores, quienes desde muy temprano estaban trabajando en el cafetal, el cañal o en el trapiche. La comida en alforja se asocia a la minuciosidad con la que las mujeres elaboraban todas las preparaciones, desde la palmeada de tortillas, hasta pensar en los productos que las acompañaría las tortillas.

La comida en alforja representa también la oportunidad de saborear la comida con las manos. No era necesario pensar en cubiertos. La tortilla envolvía los suculentos manjares que en época de las cogidas de café se degustaban bajo un árbol, escuchando los cánticos de los pajarillos y el sonar de las chicharras.

\section{Y...¿ qué me dicen de las alforjas?}

Locuciones asociadas con la alforja y su contenido resaltan en el discurso de las personas entrevistadas, las cuales tienen un sentido metafórico.

Según Sancho (2011), en el lenguaje coloquial surgen frases con un significado especial para la colectividad, que no es necesaria su explicación ampliada, puesto que al mencionarlas, las personas saben a qué se refiere ese conjunto de palabras. En el entramado verbal, según este autor, se evidencia la manera particular de entender e interpretar la realidad, y su apropiación del espacio cultural asociado con la alimentación y las tareas asociadas.

Más que los alimentos o la alforja como artículo de uso cotidiano para los campesinos antiguamente, en el habla cotidiana de las personas adultas mayores cobra sentido ciertas frases tales como: "Trae la cara más arrugada que una alforja de mecate" para referirse sobre una persona triste o preocupada.

Como insulto a varones indecisos está la frase: "pedazo de alforja mal cosida; o bien la expresión "para ese viaje no se necesitan alforjas ni compadres" se refiere al calificativo de lo sencillo o fácil de resolver un asunto.

En el caso de personas aliadas o con una amistad estrecha es común referirse a la frase "comer de la misma alforja"; mientras que cuando una persona de forma inapropiada o descontextualizada afirma alguna cosa, es común la frase: "se salió de las alforjas".

La resignación o elaboración de un duelo puede asociarse con la frase "solo al ataúd no se llevan las alforjas"; mientras que una persona puede expresar su gran enojo diciendo "ini qué alforja, ni qué ocho cuartos!,".

En relación con la comida envuelta con hojas y servilleta, la frase común para referirse a una persona son exceso de ropa "parece almuerzo envuelto", o bien para referirse a un hecho sorpresivo y el hallazgo de su descubrimiento se utiliza la frase "habrá que destapar el almuerzo, a ver qué".

Cuando se quiere minimizar un asunto o que la persona quiere aparentar una situación, la frase común es "tiene más hojas que almuerzo".

\section{Comentarios finales}

De un tema relativamente sencillo, como lo es la práctica de almacenar, conservar y transportar la comida envuelta en hojas y protegida en una alforja, se muestra una 
información sumamente relevante que contribuye a la comprensión de las prácticas alimentarias tradicionales, resaltándose elementos tales como el uso de hoja de plátano, los constituyentes de la comida del viajero y las expresiones lingüísticas que muestran un entretejido cultural complejo y de gran simbolismo.

\section{Bibliografía}

Ascoita, Carlos (2010). Historia de la alimentación en los barcos durante los viajes a América en el siglo XVI. Dirección: http://www.historiacocina.com/especiales/ articulos/abastobarcos.htm Consulta:15 de noviembre del 2015.

Cervantes, Abdiel. Alimentación, patrimonio y preservación cultural. México: Bibilioteca Jurídica Virtual, Instituto de Investigaciones Jurídicas UNAM. Dirección: http://biblio.juridicas.unam.mx/libros/6/2504/9.pdf. Consulta: 15 de diciembre del 2015.

Dobles, Cecilia; González, Fernando (2009). “Comisión Nacional para la salvaguarda del patrimonio cultural intangible: desafíos en la revitalización de la identidad costarricense". Rev. Cuadernos de Antropología (19): 223-230.

Escuela de Nutrición (2015). Descripción de tradiciones alimentarias de Costa Rica, base de datos digitalizada. Proyecto TCU-486. Universidad de Costa Rica.

Fernández, Fernando; Rodríguez, Rafael; Torres, Magaly; Oliva, María; Pérez Consuelo; Bacallao, Maritza (1997). "Características químico farmacéuticas y propiedades farmacológicas de extractos de Musa sp". Rev. Cubana de Plantas Medicinales. Mayo-agosto 2 (2): 40-44.

Harris, Marvin (1991). Bueno para comer. México: Alianza Editorial.

Pérez, Adriana. La Gastronomía Prehispánica. Saberes y Sabores de nuestros antepasados. México. Dirección: http://www.academia.edu/1905447/ Gastronom\%C3\%ADa_Prehisp\%C3\%A1nica. Consulta: 15 de diciembre del 2015.

Sancho, Leonardo (2011). "Comerse un cuento: A propósito de identidades, literatura y gastronomía". Rev. Herencia. 24 (1 y 2): 63-71.

Sedó, Patricia (2008). Glosario de cocina popular costarricense. Descripción general de alimentos, equipos, utensilios, técnicas de preparación y frases populares. San José: EDITORAMA.

Sedó, Patricia; Solano, Mayela (2014). Sembrar y comer alimentos con historia, sabor y nutrición. Reflexiones y propuestas para fortalecer la seguridad alimentaria y nutricional local. San José: Escuela de Nutrición UCR, Museo de Cultura Popular UNA.

Traversa, Olivier (2002). "Modalidades discursivas de lo alimentario". En: La cocina como patrimonio (in) tangible. Argentina: Comisión para la preservación del Patrimonio Histórico Cultural de la Ciudad de Buenos Aires. Temas de Patrimonio Cultural No. 6: pp. 47-51.

UNESCO (2003). Convención para la salvaguarda del patrimonio cultural inmaterial. Dirección: http://unesdoc.unesco.org/images/0013/001325/132540s.pdf. Consulta: 11 de diciembre del 2015.

UNESCO (2005). La tradición del boyeo y las carretas. Dirección: http://www.unesco. org/culture/ich/es/RL/la-tradicion-del-boyeo-y-las-carretas-00103. Consulta: 15 de diciembre del 2015. 
